\title{
CYTOTOXIC EFFECT OF ICD-85 (VENOM-DERIVED PEPTIDES) ON MDA-MB- 231 CELL LINE
}

\section{ZARE MIRAKABADI A (1), MAHDAVI S (1), KOOHI MK (2), TAGHAVIAN M (1)}

(1) Department of Venomous Animals and Antivenom Production, Razi Vaccine and Serum Research Institute, Karaj, Iran; (2) Faculty of Veterinary Medicine, University of Tehran, Tehran, Iran.

\begin{abstract}
Since 1987, when chemopreventive testing programs began, more than 1,000 agents and agent combinations have been selected and evaluated in preclinical studies of chemopreventive activity against various types of cancers. In the present study we aimed to provide quantitative and qualitative characterization of biological and pharmacological activities of ICD-85 on MDA-MB-231 cell line (a highly invasive breast cancer cell line) in order to gain a better understanding of the cytotoxic and apoptotic effects of this compound. For this study, the MDA-MB-231 cell line was used and the effect of ICD-85 was assayed by measuring the activity of the cytosolic enzyme lactate dehydrogenase (LDH), released into the culture medium after membrane damage. Morphological alterations of cells were investigated in the control group and cells incubated with ICD-85 as cytotoxic agent. Results showed, in the test group, that cells incubated with $16 \mu \mathrm{g} / \mathrm{mL}$ of ICD-85 had decreased cytoplasmic branching. Some cells were had ruptured and lost the continuity of their surrounding membranes while some had shrunk. Cells incubated with higher doses (above16 $\mathrm{\mu g} / \mathrm{mL}$ ) showed similar changes towards cellular normality with more severity. Results obtained from the ICD-85 stability test reveal that the effect of ICD85 on MDA-MB-231 cell line in culture medium is stable throughout the incubation time period (24 hours). It appears that ICD-85 at higher concentrations acts at the membrane level, which allows the passage of ions down the concentration gradient, resulting in osmotic changes in organelles followed by several unidentified mechanisms leading to cell death. At lower concentrations, it appears that ICD-85 can prevent cell growth by another mechanism, which may be one of the causes for apoptosis in the cell line.
\end{abstract}

KEY WORDS: venom peptides, MDA-MB-231, anticancer, necrosis, cytotoxic.

CONFLICTS OF INTEREST: There is no conflict.

\section{CORRESPONDENCE TO:}

ABBAS ZARE MIRAKABADI, Department of Venomous Animals and Antivenom Production, Razi Vaccine and Serum Research Institute, Karaj, Iran. Phone: +98 261 4502865. Email: abbas.zare8@gmail.com. 


\section{INTRODUCTION}

Although advances have been achieved in adjuvant therapies for breast cancer, many treatments cause significant and potentially life-threatening side effects such as cardiotoxicity $(8,9)$. A chemoprevention study is defined as the use of specific chemical compounds to prevent, inhibit or reduce cell growth. Since 1987, during chemoprevention testing programs, more than 1,000 agents and agent combinations have been selected and evaluated in preclinical studies of chemopreventive activities, ranging from in vitro mechanistic assays and cell-based transformation assays to carcinogen-induced and transgenic animal models $(1,7,17)$. New agents are continuously considered for development as chemopreventive drugs, whose selection is based on preliminary efficacy data, mechanistic considerations and potential for improving chemopreventive index (2).

There are reports that present the cytotoxic activity of various snake venoms, in vitro and in vivo, by employing melanoma and chondrosarcoma cells (5). It was further demonstrated that a purified protein from cobra venom was selectively cytotoxic to cancer cells $(4,6)$. Silva et al. (15) evaluated the action of the venoms from Crotalus durissus terrificus and Bothrops jararaca on Ehrlich ascites tumors and found that both venoms act directly on tumor cells. They further postulated the various mechanisms involved in the anti-tumor activity. In the present study we aimed to characterize, quantitatively and qualitatively, the biological and pharmaceutical activities of ICD-85 (biologically active peptides from venomous animals) on MDAMB-231 cell line in order to gain a better understanding of the cytotoxic, apoptotic and necrotic effects of this compound as a chemopreventive agent.

\section{MATERIALS AND METHODS ICD-85}

The active fraction of ICD-85 is a combination of three peptides, ranging from 10,000 to $30,000 \mathrm{Da}$, derived from the venoms of an Iranian brown snake (Agkistrodon halys) and a yellow scorpion (Hemiscorpius lepturus). This fraction was formulated and provided by the corresponding author. The ICD-85 peptides were selected based on a study of crude venom cytotoxicity. The crude venom showed antigrowth activity on the MBA-MD231 cell line. Then, the venoms were fractionated, the active peptides were isolated and, subsequentially, tested on the same cell line. Enzymatic characterization of the peptides was not performed. 


\section{Cell Line}

The MDA-MB-231 breast cancer cell line was kindly provided by Professor Holger Kalthoff from Christian-Albrechts University (Kiel, Germany). These cells were plated in suitable culture flasks in Dulbecco's Modified Eagle's Medium (DMEM) (Sigma, Germany) supplemented with $10 \%$ fetal calf serum and $1 \%$ L-glutamin plus $0.5 \%$ penicillin/streptomycin and incubated at $37^{\circ} \mathrm{C}(10,11)$.

\section{Quantification of ICD-85 Cytotoxicity}

Cells used in this study were harvested by trypsination $(0.5 \%$ trypsin in phosphatebuffered saline [PBS]), resuspended in fresh medium and distributed into three (12well) plates at about $10^{4}$ cells/well $(10,11)$. After 24 hours of incubation, the cultures were washed with serum free medium (SFM). For dose determination, various concentrations - 1, 2, 4, 8, 16, 32, 64, $128 \mu \mathrm{g} / \mathrm{mL}$ SFM of ICD-85 - were added and the cells were incubated for 48 hours. Control culture was treated with an equal amount of SFM (utilized to avoid the possible interaction between ICD-85 and FBS) $(10,11)$.

Toxicity was assayed by measuring the activity of the cytosolic enzyme, lactate dehydrogenase (LDH), released into the culture medium after membrane damage. Samples from clarified medium of treated and untreated control wells were taken after intervals of $0.5,1,2,4$ and 8 hours of incubation and the LDH activity was measured using the cytotoxicity assay, CytoTox $96 \AA$ (Promega, USA) associated with a fully automated microplate reader photometer. Damage and morphological changes in the cell line were investigated by light phase contrast microscopy and photos were taken at each evaluation moment.

\section{Stability of ICD-85 in Culture}

To examine variations of ICD-85 activity in the liquid medium, culture medium containing ICD-85 at the lowest concentration $(1 \mu \mathrm{g} / \mathrm{mL})$ was incubated at $37^{\circ} \mathrm{C}$ in a fully humidified atmosphere. After a 24-hour incubation, ICD-85 solution samples were tested on the MDA-MB-231 cell line by measuring LDH. 


\section{Statistical Analysis}

Data were analyzed using student's t-test with statistical significance for $p<0.05$.

\section{RESULTS}

The MDA-MB-231 cells in the control culture samples were homogenously distributed into the culture field. They exhibited polygonal shapes with distinct boundaries and homogenous or slightly granulated cellular contents. The cells were thin and elongated with tapered ends in cytoplasmic branches (metastatic branches). In test groups, cells incubated with smaller doses (less than $8 \mu \mathrm{g} / \mathrm{mL}$ of ICD-85) were almost similar in morphological appearance to the control cells; and most MDA-MB231 cells conserved their common characteristic structure, except for the occurrence of cellular swelling and diminished cytoplasmic branches (Figure $1-A$ and $A 1$ ). Cellular swelling and cytoplasmic branch reduction occurred after incubation with the $16 \mu \mathrm{g} / \mathrm{mL}$ dose. Additionally, some cells were ruptured and cell number decreased (Figure 1 - B and B1). Cells incubated with higher doses (above $16 \mu \mathrm{g} / \mathrm{mL}$ ), presented similar changes towards normality. In this case, several cells appeared rounded rather than elongated. Furthermore, few cells still maintained their MDA-MB231 common appearance. 


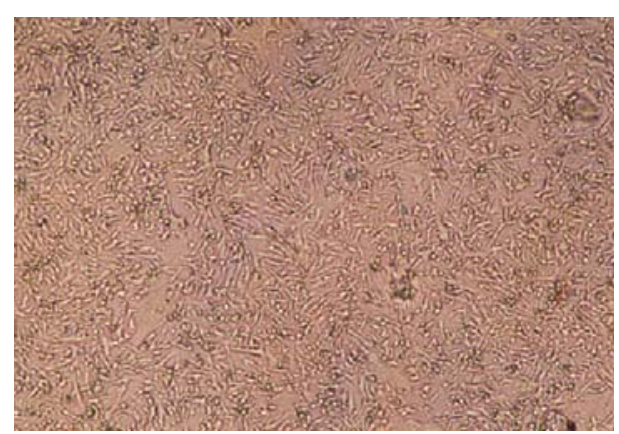

A

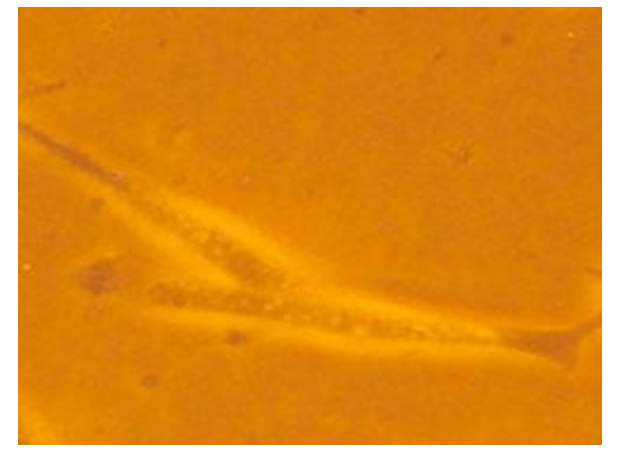

A1

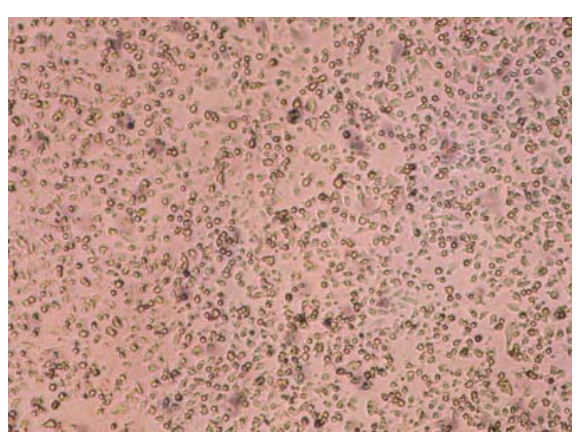

B

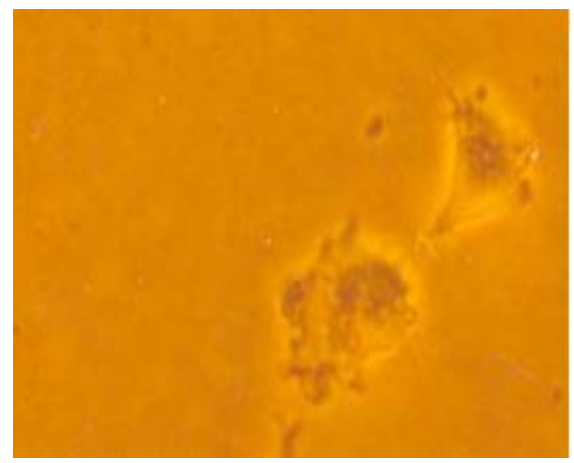

B1

Figure 1. MDA-MB-231 cells before and after treatment with ICD-85. MDA-MB-231 control cells ( $\mathbf{A}$ and $\mathbf{A} \mathbf{1}$ ); note the normal appearance of elongated cells. MDA-MB231 cells treated with $16 \mu \mathrm{g} / \mathrm{mL}$ of ICD-85 (B and B1). Cells present roundish shape and decreased cytoplasmic branches.

Results obtained from the ICD-85 stability test revealed that ICD-85 is stable throughout the incubation time period (24 hours) in the culture medium and that its cytotoxic effects on the MDA-MB-231 cell line are significant. LDH released from cultured cells and exposed to a biomaterial provides a sensitive and accurate marker for cellular toxicity. As shown in Table 1, ICD-85 induced identical dose-response effect on MDA-MB-231 cells, releasing 9, 13, 15, 19, 23, 29, 30 and 34 IU of LDH after 30 minutes (at respective concentrations of 1, 2, 4, 8,16, 32, 64 and 128 $\mu \mathrm{g} / \mathrm{mL})$. 
Table 1. Comparison of LDH activity in cultured media $30 \mathrm{~min}$. after incubation of MDA-MB-231 cell line treated with ICD-85

\begin{tabular}{cccc}
\hline Groups & $\begin{array}{c}\text { ICD-85 } \\
\text { concentration } \\
\mu \text { /mL }\end{array}$ & $\begin{array}{c}\text { ICD-85 treated cells } \\
\text { LDH activity (IU) }\end{array}$ & p values \\
\hline 1 & 0 & 9 & NS \\
\hline 2 & 1 & $9 \pm 3$ & $\mathrm{NS}$ \\
\hline 3 & 2 & $13 \pm 5$ & $\mathrm{p}>0.05$ \\
\hline 4 & 4 & $15 \pm 5$ & $\mathrm{p}>0.01$ \\
\hline 5 & 8 & $19 \pm 4$ & $\mathrm{p}>0.001$ \\
\hline 6 & 16 & $23 \pm 5$ & $\mathrm{p}>0.001$ \\
\hline 7 & 32 & $29 \pm 4$ & $\mathrm{p}>0.001$ \\
\hline 8 & 64 & $30 \pm 5$ & $\mathrm{p}>0.001$ \\
\hline 9 & 128 & $34 \pm 7$ & \\
\hline
\end{tabular}

Note: all groups were compared with Group 1 (untreated cells). The tests were repeated six times. NS: not significant.

\section{DISCUSSION}

Evidence from basic research and from experiments on animal models and cell culture systems supports the concept that several compounds, including natural products, may offer protection against organ site carcinogenesis $(3,16)$. These biological products or natural phytochemicals, either as single agents or as adjuvants, may represent valuable lead compounds for preventive or therapeutic interventions (6).

Crude snake venoms and their isolated peptides have proven effective cancer cell inhibitors (12-14).

The MDA-MB-231 cell line was employed in the current study due to its extremely invasive behavior $(10,11)$. This investigation showed that the damage induced in the cell line by ICD-85 is direct. The cytotoxicity was remarkable and cell survival was reduced by the two highest concentrations (64 and128 $\mu \mathrm{g} / \mathrm{mL}$ ). Considering the rapid effects observed within 30 minutes - including the lysis of organelle membranes that immediately caused cell death - we suggest that this biological product (ICD-85) acts at the membrane level at high concentrations. The cytotoxicity assay that measured 
LDH activity can also detect whether cells and apoptotic bodies remain enclosed by intact plasma membrane, and thus, can be used to differentiate between apoptosis and necrosis. Since ICD-85, at high concentrations, acts at the membrane level, it allows the passage of ions down their concentration gradient, resulting in osmotic changes in organelles followed by several unidentified mechanisms leading to cell death. This process may be involved in cell line apoptosis, as a result of ICD-85 treatment. In this respect, apoptosis and other forms of cell death could be set in motion by diverse stimuli such as chemical toxicity, radiation or genotoxic damage.

The ICD-85 effect was also tested on two additional cell lines, human leukemia (HL$60)$ and Vera cell line. The results of this peptide on both were almost similar to MDA-MB-231 (unpublished data). At $7 \mu \mathrm{g} / \mathrm{mL}$ concentration, on the HL-60 cell line, ICD-85 could transform the growth trends towards normality. The ICD-85 effect on normal cells (MRC5), at low concentrations (5, 10 and $15 \mu \mathrm{g} / \mathrm{mL}$ ), after 24 hour incubation, showed no significant cell damage. However, when concentration increased and was above $20 \mu \mathrm{g} / \mathrm{mL}$, the cytotoxic effect of ICD-85 was evident. It appears that ICD-85 acts selectively on cancer cells at low concentration.

Despite the great advances in understanding the morphological and biochemical alterations associated with substances that can induce cell injury, the knowledge acquired is still insufficient to establish which changes lead to cell death and which are secondary disturbances.

The current study aimed to clarify some of the ICD-85 cytotoxic effects on cultured cell lines. Several conclusions can be reached from this study. It is clear that the cytotoxic effects are dose- and time-dependent, and ICD-85 kills cells by different mechanisms. The membrane damage is more prominent and clear in the early stages of toxicity, while other forms of cell damage - including swelling, rupture or necrosis - occurred in the later stages. Recently, local injection of ICD-85 at breast cancer targets was carried out and produced anti-angiogenesis features, lifespan increase and tumor size decrease in mice presenting induced breast cancer (under publication). Based on the results obtained herein and in in vivo studies, we hope that a new biologically active drug against cancer will be developed. 


\section{REFERENCES}

1 ANTMAN KH. The history of arsenic trioxide in cancer therapy. Oncologist, 2001, 6, $1-2$.

2 ARDJMAND AR., ALIMOGHADDAM K., ZAKER F., GHAVAMZADEH A., JAHANI M. Arsenic trioxide selectively induces apoptosis within the leukemic cells of APL patients with $\mathrm{t}(15 ; 17)$ translocation possibly through the Fas pathway. IJHOBMT, 2004, 1, 13-17.

3 BLACK RA., WHITE JM. ADAMs: focus on the protease domain. Curr. Opin. Cell. Biol., 1998, 10, 654-9.

4 BRAGANCA BM., PATEL NT., BADRINAH PG. Isolation and properties of a cobra venom factor selectively cytotoxic to Yoshida sarcoma cells. Biochim. Biophys. Acta, 1967, 136, 508-20

5 CHAIM-MATYAS A., OVADIA M. Cytotoxic activity of various snake venoms on melanoma B16F10 and chondrosarcoma. Life Sci., 1987, 40, 1601-7.

6 CHIH-HSIN T., RONG-SEN Y., CHAO-ZONG L., TUR-FU H., WEN-MEI F. Differential susceptibility of osteosarcoma cells and primary osteoblasts to cell detachment caused by snake venom metalloproteinase protein. Toxicon, 2004, 43, 11-20.

7 FENAUX P., CHEVERT S., GUERCI A. Long-term follow-up confirms the benefit of all-trans retinoic acid in acute promyelocytic leukemia. Leukemia, 2000, 14, 137177.

8 HORTOBAGYI GN., BUZDAR AU. Current status of adjuvant systemic therapy for primary breast cancer: progress and controversy. CA Cancer J. Clin., 1995, 45, 199226.

9 JENSEN BV., SKOVSGAARD T., NIELSEN SL. Functional monitoring of anthracycline cardiotoxicity: a prospective, blinded, long-term observational study of outcome in 120 patients. Ann. Oncol., 2002, 13, 699-709

$10 \mathrm{KOOHI}$ MK., IVELL R., WALTHER N. Transcriptional activation of the oxitocin promoter by oestrogens uses a novel non-classical mechanism of oestrogen receptor action. J. Neuroendocrinol., 2005, 17, 197-207.

$11 \mathrm{KOOHI}$ MK., WALTHER N., IVELL R. A novel molecular assay to discriminate transcriptional effects caused by xenoestrogens. Mol. Cell. Endocrinol., 2007, 276, 45-54. 
12 LIPPS BV. Novel snake venom proteins cytolytic to cancer cells in vitro and in vivo systems. J. Venom. Anim. Toxins, 1999, 5, 173-83.

13 MACARTHY JB., BASARA ML., PALM SL., SAS DF., FURCHT LT. The role of cell adhesion protein-laminin and fibronectin in the movement of malignant and metastatic cell. Cancer Metastasis Rev., 1985, 4, 125-52.

14 MARKLAND JR FS. Antitumor action of crotalase, a defibrinogenating snake venom enzyme. Semin. Thromb. Hemost., 1986, 12, 284-90.

15 SILVA RJ., FECCHIO D., BARRAVIERA B. Antitumor effects of snake venoms. J. Venom. Anim. Toxins, 1996, 2, 79-90.

16 WU WB., CHANG SC., LIAU MY., HUANG TF. Purification, molecular cloning and mechanism of action of graminelysin $I$, a snake-venom-derived metalloproteinase that induces apoptosis of human endothelial cells. Biochem. J., 2001, 357, 719-28.

17 ZHEN-YI W., ZHU-CHEN. Differentiation and apoptosis induction therapy in acute promyelocytic leukemia. Lancet Oncol., 2000, 1, 101-6. 